\title{
Regulation of cell growth by fatty acid-CoA ligase 4 in human hepatocellular carcinoma cells
}

\author{
Young Kwan Sung ${ }^{1,4}$, Mi Kyung Park ${ }^{1}$, \\ Su Hyung Hong ${ }^{2}$, Sun Young Hwang ${ }^{3}$, \\ Mi Hee Kwack ${ }^{1}$, Jung Chul Kim ${ }^{1}$ \\ and Moon Kyu Kim ${ }^{1}$ \\ ${ }^{1}$ Department of Immunology \\ School of Medicine, Kyungpook National University \\ Daegu 700-422, Korea \\ ${ }^{2}$ Department of Dental Microbiology \\ School of Dentistry, Kyungpook National University \\ Daegu 700-412, Korea \\ ${ }^{3}$ Immunomodulation Research Center \\ University of Ulsan \\ Ulsan 680-749, Korea \\ ${ }^{4}$ Corresponding author: Tel, 82-53-420-4874; \\ Fax, 82-53-423-4628; E-mail, ysung @knu.ac.kr
}

Accepted 21 May 2007

Abbreviations: AA, arachidonic acid; FACL4, fatty acid-CoA ligase 4; HCC, hepatocellular carcinoma

\footnotetext{
Abstract

Fatty acid-CoA ligase 4 (FACL4) is a central enzyme controlling the unesterified free arachidonic acid (AA) level in cells and the free AA is known to induce apoptosis. We have recently reported that expression of FACL 4 is upregulated in about $40 \%$ of human hepatocellular carcinoma (HCC) and $50 \%$ of HCC cell lines, suggesting that FACL4 may be involved in liver carcinogenesis. In this study, we investigated whether HCC cell growth is regulated by FACL4. Immunoblot analysis showed that SNU 398 cells express very low or no detectable level of FACL4. We, therefore, transfected the SNU 398 cells with FACL4 expression vector, and clones expressing FACL4 were pooled and analyzed. We found that forced expression of FACL4 in SNU 398 promotes the growth of cells. In addition, we observed that triacsin C, a FACL4 inhibitor, inhibits the growth of Hep 3B cell line which expresses high level of endogenous FACL4. We also found that the triacsin C-mediated growth inhibition in Hep $3 B$ cells results from the induction of apoptosis with evidence of $\mathrm{Bcl}-2$ reduction. Altogether, our data show that FACL4 affects HCC cell growth and suggest that modulation of FACL4 expression/activity is an approach for treatment of HCC.
}

Keywords: apoptosis; arachidonic acid; carcinoma, hepatocellular; long-chain-fatty-acid-CoA ligase; tri$\operatorname{acsin} \mathrm{C}$

\section{Introduction}

Fatty acid-CoA ligase 4 (FACL4) is a central enzyme controlling the unesterified arachidonic acid (also called free AA) level in cells (Cao et al., 1998). Free AA entering cells exogenously or released endogenously is rapidly converted to AA-CoA esters by the catalytic action of FACL, particularly by the AA-preferring FACL4 (Wilson et al., 1982; Cao et al., 1998). Several lines of evidence indicated that the level of free AA in cells regulate apoptosis (Reid et al., 1991; Hayakawa et al., 1993; Sapirstein et al., 1996; Tang et al., 1996; Chan et al., 1998). Also, overexpression of FACL4 prevented $A A$-induced apoptosis by reducing the level of intracellular free AA (Cao et al., 2000). These findings, together with overexpression of FACL4 in colon adenocarcinoma strongly suggest that the FACL4 pathway may be important in colon carcinogenesis (Cao et al., 2001).

Hepatocellular carcinoma (HCC) is one of the most common tumors worldwide and is one of the leading causes of death among cancer patients in Korea. Identification of genes that are overexpressed in HCC is of importance to understand liver tumorigenesis and to develop diagnostic and therapeutic targets. Recently, we have shown for the first time that FACL4 is upregulated in $\mathrm{HCC}$ compared with adjacent normal liver tissues (Sung et al., 2003b). We found that 14 out of $37(37.8 \%)$ HCC express moderate to strong FACL4 in tumor cells, whereas both normal adult and fetal liver tissues showed very weak to no detectable expression by immunostaining. In addition, we found that 4 out of $8(50 \%)$ human hepatoma cell lines express high levels of FACL4 by Northern blot analysis (Sung et al., 2003b). These results show that FACL4 could be a new molecular marker for $\mathrm{HCC}$ and suggest that FACL4 pathway may be involved in liver carcinogenesis. In this study, we investigated whether $\mathrm{HCC}$ cell growth is regulated by FACL4. We found that forced expression of FACL4 promotes the growth of HCC cells. In addition, we observed that triacsin $\mathrm{C}$, a FACL4 inhibitor, inhibits the growth of the Hep 3B cells by 
induction of apoptosis with evidence of Bcl-2 reduction.

\section{Materials and Methods}

\section{Cell lines}

Cell lines derived from hepatocellular carcinomas (HCCs) were purchased from Korea Cell Line Bank (Seoul). Hep G2 and Hep 3B cells were grown in DMEM with $10 \%$ FBS. The SNU 354, SNU 368, SNU 398, SNU 423, SNU 449, and SNU 475 cells (Park et al., 1995) were cultured in RPMI 1640 with $10 \%$ FBS.

\section{Construction of FACL4 expression vector}

Expression plasmid was constructed using pcDNA3.1/ Myc-His(+) B vector (Invitrogen, Carlsbad, CA) as described (Farooq et al., 2001) with minor modifications. Briefly, FACL4 cDNA was prepared by RT-PCR and it was subcloned into the BamHI and Xhol sites of the pcDNA3.1/Myc-His(+) B vector, generating pFACL4/Myc-His. The orientation and accuracy of the sequences were confirmed by sequencing. The primers for PCR were 5'-CGGGATCCAACGCTATGGCAAAGAGAATA-3' and 5'-CCGCTCGAGCGTTTGCCCCCATACATTCGT-3'. The BamHI (GGATCC) and Xhol (CTCGAG) sites engineered for cloning are underlined.

\section{Construction of stable cell line}

The SNU 398 cells were grown to $50-80 \%$ confluence and then they were transfected with the control vector [pcDNA3.1/Myc-His(+) B vector] or with the pFACL4/Myc-His vector with using Lipofectamine. After $2 \mathrm{~d}$, the cell cultures were diluted $1: 10$ in selection medium (RPMI $10 \%$ medium with $400 \mu \mathrm{g} / \mathrm{ml} \mathrm{G} 418$ ), and after 4 weeks, individual clones were isolated and examined for the expression of FACL4.

\section{Immunoblot analysis}

The total cell lysates were prepared and the protein concentration was measured using the BCA protein assay (Pierce, Rockford, IL). Protein samples $(30 \mu \mathrm{g} / \mathrm{lane})$ were separated on $10 \%$ polyacrylamide gel and then transferred to nitrocellulose membranes. The membranes were blocked with $6 \%$ milk in PBS for $1 \mathrm{~h}$, and they were probed with anti-human FACL4 antibody at a 1:2,000 dilution. HRP-conjugated donkey antirabbit Ig (Amersham, Buckinghamshire, UK) was used as the secondary antibody at a 1:5,000 dilution. Bands were visualized using ECL Plus (Amersham). Anti-human FACL4 antibody (a gift from Dr. Prescott in U. of Utah, USA) was raised in rabbit against a synthesized peptide $(\mathrm{H} 2 \mathrm{~N}-$ MAKRIKAKPTSDKPGC-amide) that corresponds to the deduced $\mathrm{N}$-terminal sequence of human FACL4. For the detection of FACL4/ Myc-His fusion protein, cell lysates were also probed with mouse anti-c-myc antibody (Roche, Mannheim, Germany). HRP-conjugated sheep anti-mouse Ig (Amersham, Buckinghamshire, UK) was used as the secondary antibodies at a 1:5,000 dilution. For the detection of $\mathrm{Bcl} 2$, cells were treated with triacsin C for 24 and $48 \mathrm{~h}$, and probed with mouse anti-Bcl-2 antibody (Roche, Germany).

\section{Cell viability assay}

Cells were plated overnight at a density of 5,000 cells/well in 96-well plates with 10\% FBS-supplemented RPMI medium. The medium was then changed to serum-free medium with various concentrations of triacsin C (Biomol, Plymouth Meeting, PA), and the cells were incubated for the indicated times. The MTT assay was employed to check cell viability as previously described (Sung et al., 2003a). Triacsin C was dissolved in DMSO. The final DMSO concentration in the media was $0.1 \%$.

\section{Analysis of the cell cycle distribution}

The cells were collected and washed with PBS and then fixed in $70 \%$ ethanol at $4{ }^{\circ} \mathrm{C}$ overnight. The cell cycle distribution was analyzed by flow cytometry as was previously described (Farooq et al., 2003).

\section{Apoptosis assay}

This assay was performed using a Cell Death Elisa kit (Roche, Mannheim, Germany), following the manufacturer's instructions. Briefly, after treatment with $20 \mu \mathrm{M}$ triacsin $\mathrm{C}$ for 24 and $48 \mathrm{~h}$, cytoplasmic extracts were prepared from 10,000 cells and DNA-histone complexes were measured by reading optical density at $405 \mathrm{~nm}$ using a microplate reader.

\section{Statistical analysis}

The $t$-test was used to determine the statistical significance of differences. Probability $(P)$ values less than 0.05 were considered statistically significant. 


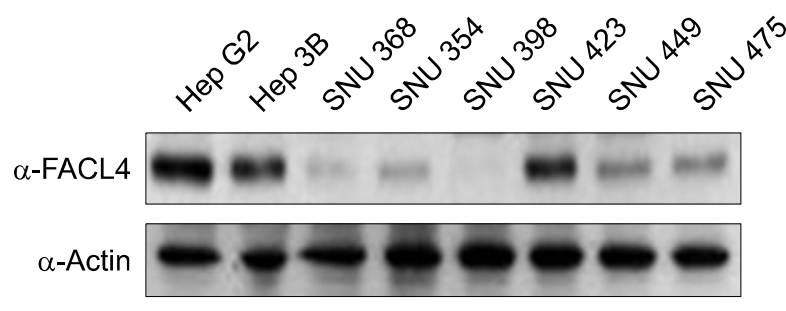

Figure 1. FACL4 expression in the HCC cell lines. Expression of FACL4 protein was investigated in 8 human HCC cell lines using anti-human FACL4 antibody (top panel). Membranes were stripped and reprobed with mouse anti-actin antibody (bottom panel).

\section{Results}

\section{Expression of FACL4 in the hepatocellular carcinoma cell lines}

To investigate whether HCC cell growth is regulated by FACL4, we checked the FACL4 expression in 8 human HCC cell lines by performing immunoblot analysis using rabbit polyclonal antihuman FACL4 antibody. A major band with an approximate molecular weight of $75 \mathrm{KDa}$ was detected (Figure 1). Similar to the previous Northern blot analysis (Sung et al., 2003b), Hep G2, Hep 3B and SNU 423 cells expressed a high level of FACL4, whereas the SNU 354, SNU 368 and SNU 398 cells expressed very low or no detectable levels of FACL4.

\section{The forced expression of FACL4 promotes the growth of SNU 398 cells}

To assess whether FACL4 affects the growth of HCC cells, we transfected SNU 398 cells with a FACL4 expression vector (pFACL4/Myc-His). The individual G418 resistant clones were isolated after a few weeks and three clones expressing FACL4 were pooled and named as the 'Sense pool'. SNU 398 cells were also transfected with an empty vector [pcDNA3.1/Myc-His(+) B] and the G418 resistant clones were pooled and named as the 'Control pool'. Forced expression of FACL4/MycHis fusion protein in the 'Sense pool' was confirmed by immunoblot analysis with using antihuman FACL4 antibody and anti-c-Myc antibody (Figure 2A). Measurements of the effect of FACL4 on cell growth revealed that cell growth was significantly promoted in the cells that expressed FACL4 (Figure 2B). We also found that forced expression of FACL4 in SNU368 cells, which express very low level of FACL4, promotes the cell growth by $40 \%$ (data not shown).

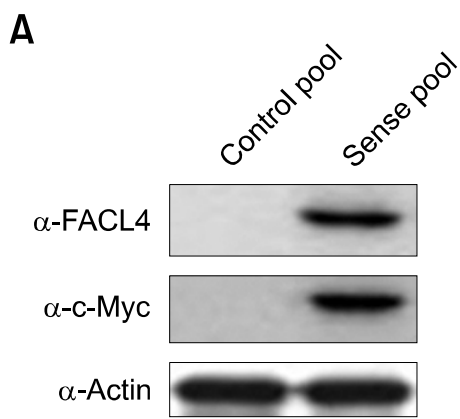

B
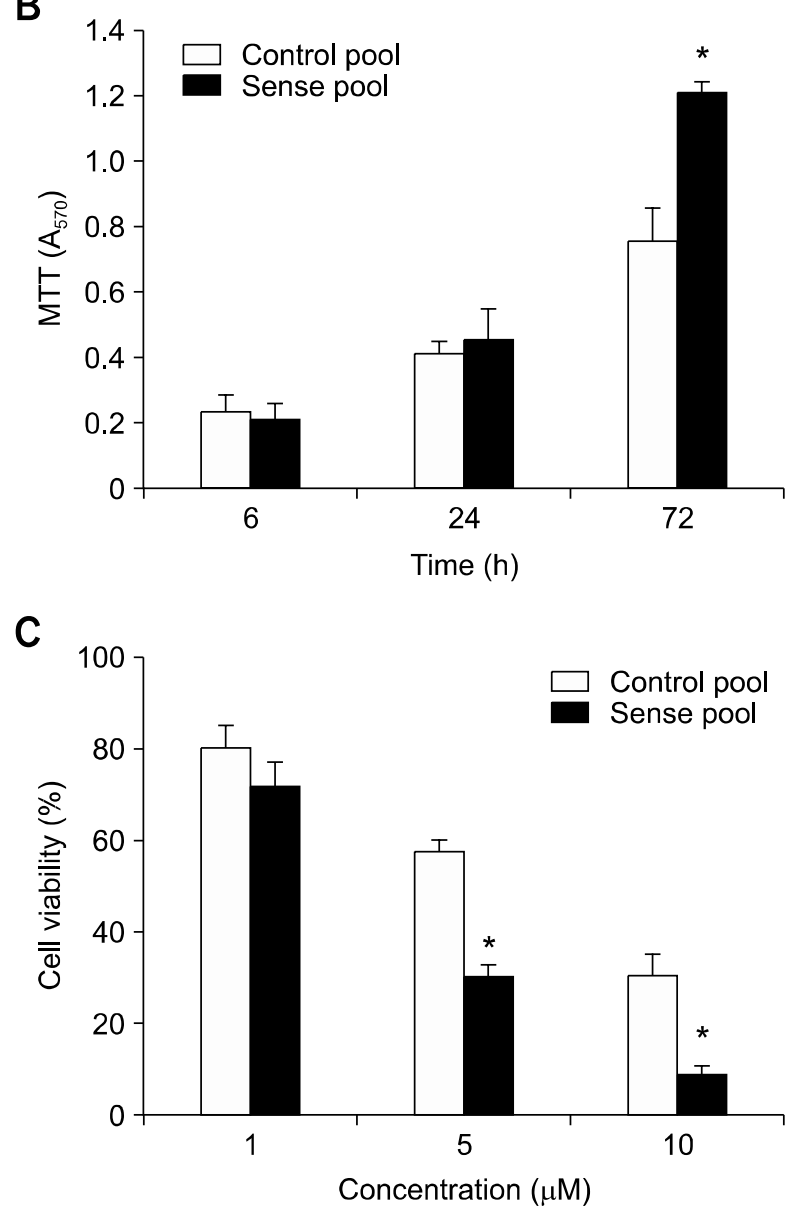

Figure 2. (A) Forced expression of FACL4 in SNU 398 cell line. Expression of FACL4/Myc-His fusion protein was investigated using anti-human FACL4 antibody (top panel) and c-myc antibody (middle panel). Three clones expressing FACL4 were pooled and named as 'Sense pool'. Also, SNU 398 cells were transfected with an empty vector and G418 resistant clones were pooled and named as 'Control pool'. (B) MTT assay showed increased cell proliferation in 'Sense pool'. Values represent the means \pm standard errors of 5 determinations per experiment from 3 independent experiments ( $P<0.05$ compared to the control). (C) Comparision of cytotoxic effect of triacsin $C$. Values represent the means \pm standard errors of 5 determinations per experiment from 3 independent experiments $\left({ }^{*} P<0.05\right.$ compared to the control). 
A

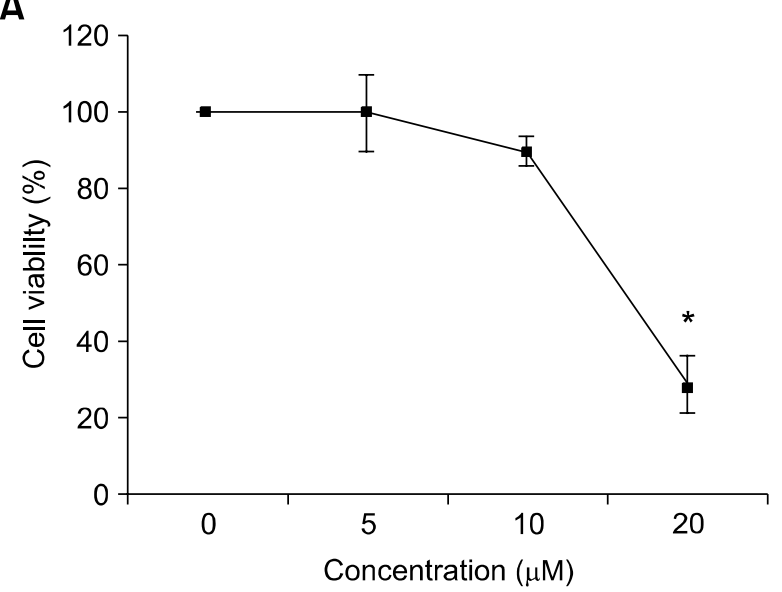

B

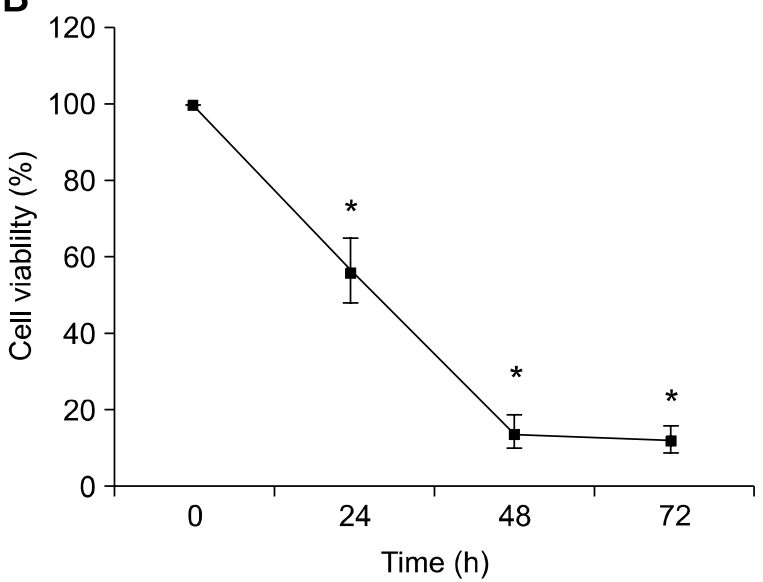

Figure 3. Growth inhibition of the Hep 3B cell line by triacsin C treatment. (A) Dose-dependent growth inhibition. Cells were treated with triacsin $\mathrm{C}$ for 72 h. (B) Time-dependent growth inhibition with $20 \mu \mathrm{M}$ triacsin $\mathrm{C}$. The MTT assay was employed to measure the cell viability in both cases. Data are the means \pm standard errors of 5 determinations per experiment from 3 independent experiments $\left({ }^{*} P<0.05\right)$.

A
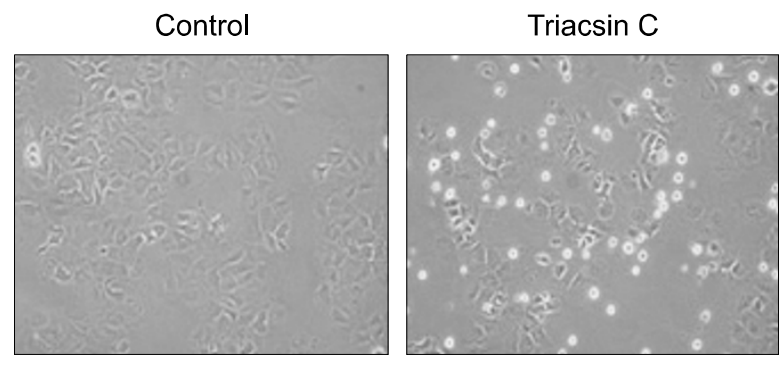

C

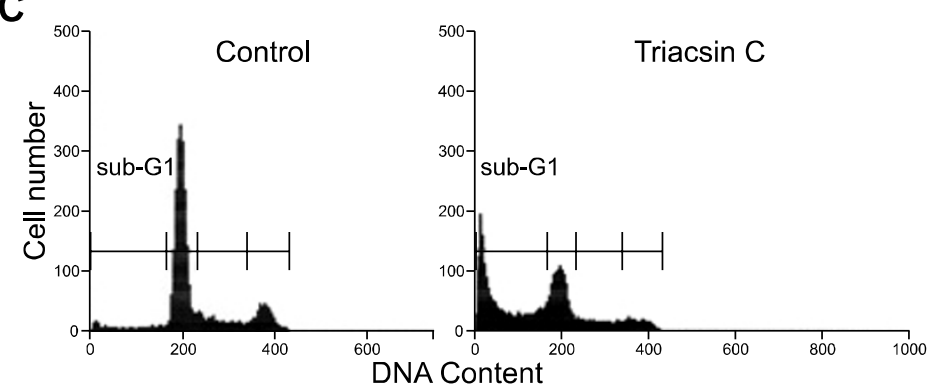

B

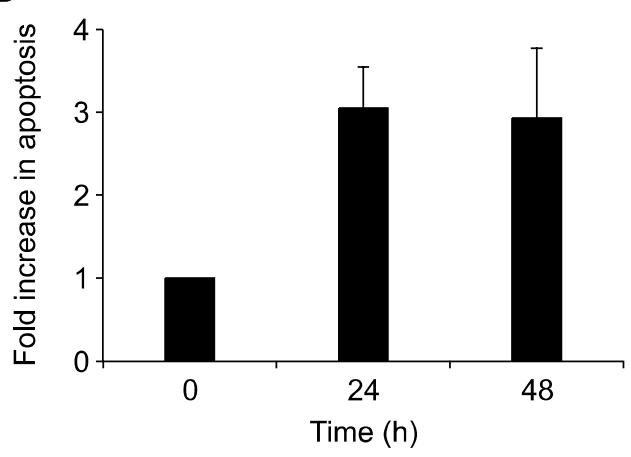

D

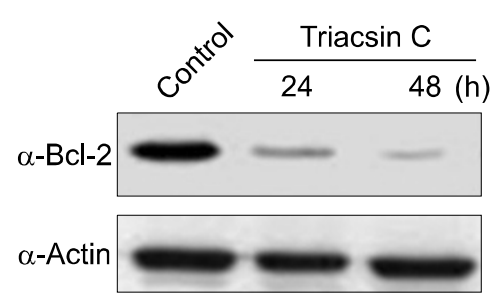

Figure 4. (A) Phase-contrast microscopy of morphological changes associated with apoptosis in Hep 3B cells treated with $20 \mu \mathrm{M}$ triacsin $\mathrm{C}$ for $30 \mathrm{~h}$. (B) Cell death ELISA assay. Cells were treated with $20 \mu \mathrm{M}$ triacsin $\mathrm{C}$ for 24 and $48 \mathrm{~h}$. The results are presented as the fold increase in apoptosis relative to the controls that received DMSO only. Data are the means \pm standard errors of 2 determinations per experiment from 2 independent experiments. (C) Cell cycle analysis using flow cytometry. A representative DNA histogram is shown. Cells were exposed to either DMSO or $20 \mu \mathrm{M}$ triacsin C for $48 \mathrm{~h}$. (D) Immunoblot analysis of Bcl-2. Cells were treated with $20 \mu \mathrm{M}$ triacsin $\mathrm{C}$ for 24 and $48 \mathrm{~h}$.

\section{Triacsin C inhibits the growth of Hep 3B cells}

Triacsin C, a FACL4 inhibitor, treatment resulted in dose- and time-dependent growth inhibition in Hep $3 \mathrm{~B}$ cells (Figure 3 ). Morphological changes were evident in cells cultured with triacsin $C$ in both serum-free and $10 \%$ serum-containing medium: the cells rounded up and detached from the plate
(Figure 4A). We also quantitated the extent of apoptosis with the Cell Death Elisa Assay, which measures DNA fragments associated with cytoplasmic histone. Treatment for 24 and $48 \mathrm{~h}$ with 20 $\mu \mathrm{M}$ triacsin $\mathrm{C}$ produced about 3.0 -fold increases in apoptosis (Figure 4B). Analysis of the cell cycle distribution by flow cytometry showed that the 


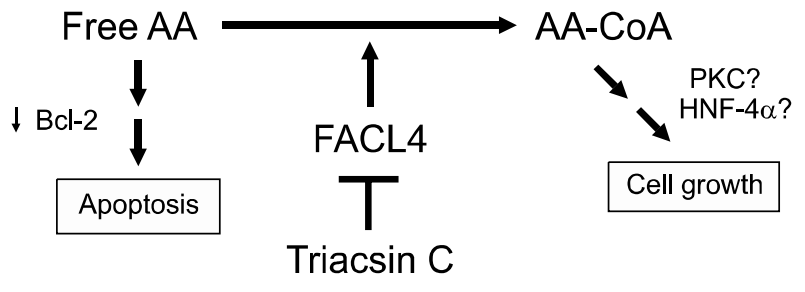

Figure 5. Simple schematic based on this study and previous reports from Tang et al. (1996), Faergeman and Knudsen (1997), Kluck et al. (1997), Hertz et al. (1998), Chan et al. (1998), Cao et al. (2000, 2001), Sung et al. (2003b), and Monjazeb et al. (2006).

population of cells in sub-G1 phase, representing apoptotic cells, increased significantly in response to triacsin $\mathrm{C}$ treatment (Figure 4C). We also observed that $\mathrm{Bcl}-2$ level is significantly decreased as defined by immunoblot analysis (Figure 4D). Consistent with the above findings, we found that cytotoxic effect of triacsin C is significantly higher in SNU398 cells engineered to over-express FACL4 (Figure 2C).

\section{Discussion}

FACL4 is a central enzyme controlling the unesterified free AA level in cells (Cao et al., 1998). In this study, we have shown that forced expression of FACL4 promotes the growth of SNU 398 HCC cells. This result is in accord with the recent report of growth inhibition of Hep 3B cells by disrupting the expression of endogenous FACL4 using siRNA (Liang et al., 2005). In addition, in a preliminary study, we found that antisense oligonucleotides directed against the translation start region of the FACL4 suppress Hep 3B cell growth (unpublished results). Altogether, these results show that FACL4 plays a growth-promoting role in hepatocellular carcinoma. The growth promotion by overexpression of FACL4 might be due to depletion of free $A A$, which is known to induce apoptosis via activation of caspase-3 (Chan et al., 1998; Cao et al., 2000; Monjazeb et al., 2006). This scenario is in line with the reduction of AA-induced apoptosis by overexpression of FACL4 in human kidney epithelial 293 cells (Cao et al., 2000). Overexpression of FACL4, thereby increasing the level of AA-CoA esters, might also promote cell proliferation and cell growth by regulating signaling molecules such as protein kinase $\mathrm{C}$ and binding to transcription factors such as hepatic nuclear factor- $4 \alpha$, since fatty acyl-CoA esters have been shown to be involved in these processes (Faergeman and Knudsen, 1997, Hertz et al., 1998). Further studies are needed to elucidate the biochemical pathways involved in the FACL4mediated growth promotion.

We also showed here that triacsin $C$ inhibits the growth of the Hep 3B cells which express a high level of endogenous FACL4. Morphological changes, together with Cell Death Elisa Assay and cell cycle distribution analysis showed that triacsin C induces apoptosis in Hep 3B cells. Our data is consistent with the recent report of the induction of apoptosis in HT29 and HCT-116 human colon cancer cell lines by triacsin C (Cao et al., 2000; Monjazeb et al., 2006). In addition, in view of the fact that the free AA down-regulates $\mathrm{Bcl}-2$ (Cao et al., 2000), we anticipated that the level of $\mathrm{Bcl}-2$ would be reduced during triacsin $\mathrm{C}$-induced apoptosis in Hep 3B cells, and this has proved to be the case (Figure 4D). Therefore, triacsin C, by inhibition of FACL4 activity, is believed to induce accumulation of free $A A$, which in turn induces apoptosis. Our data also suggests that triacsin C-induced apoptosis in Hep 3B cells may be due to mitochondrial cytochrome $c$ release leading to caspase-3 activation since $\mathrm{Bcl}-2$ is known to prevent these processes (Kluck et al., 1997; Yang et al., 1997). Indeed, Monjazeb et al. (2006) very recently showed caspase-3 activation in colon cancer HCT-116 cells by triacsin C.

In conclusion, we, first time to our knowledge, show that overexpression of FACL4 promotes the growth of HCC cells. We also showed that triacsin $\mathrm{C}$ induces apoptosis of $\mathrm{HCC}$ cells via $\mathrm{Bcl}-2$ reduction. Our data demonstrate that FACL4 is of importance in human hepatocarcinogenesis and suggest that modulation of FACL4 expression/ activity is an approach for treatment of HCC.

\section{Acknowledgement}

We are grateful to Dr. S. Prescott for anti-human FACL4 antibody. This work was supported by BioMedical Research Institute grant, Kyungpook National University Hospital (2006).

\section{References}

Cao Y, Traer E, Zimmerman GA, Mclntyre TM, Prescott SM. Cloning, expression, and chromosomal localization of human long-chain fatty acid-CoA ligase 4 (FACL4). Genomics 1998;49:327-30

Cao Y, Pearman AT, Zimmerman GA, Mclntyre TM, Prescott SM. Intracellular unesterified arachidonic acid signals apoptosis. Proc Natl Acad Sci USA 2000;97:11280-5

Cao Y, Dave KB, Doan TP, Prescott SM. Fatty acid CoA ligase 4 is up-regulated in colon adenocarcinoma. Cancer Res 2001;61:8429-34 
Chan TA, Morin PJ, Vogelstein B, Kinzler KW. Mechanisms underlying nonsteroidal antiinflammatory drug-mediated apoptosis. Proc Natl Acad Sci USA 1998;95:681-6

Faergeman NJ, Knudsen J. Role of long-chain fatty acyl-CoA esters in the regulation of metabolism and in cell signalling. Biochem J 1997;323:1-12

Farooq M, Kim YH, Im SU, Chung EJ, Hwang SY, Sohn MY, Kim MK, Kim JC. Cloning of BNIP3h, a member of proapoptotic BNIP3 family genes. Exp Mol Med 2001;33:169-73

Farooq M, Hwang SY, Park MK, Kim JC, Kim MK, Sung YK. Blocking endogenous glypican-3 expression releases Hep 3B cells from G1 arrest. Mol Cells 2003;15:356-60

Hayakawa M, Ishida N, Takeuchi K, Shibamoto S, Hori T, Oku $\mathrm{N}$, Ito F, Tsujimoto M. Arachidonic acid-selective cytosolic phospholipase A2 is crucial in the cytotoxic action of tumor necrosis factor. J Biol Chem 1993;268:11290-5

Hertz R, Magenheim J, Berman I, Bar-Tana J. Fatty acyl-CoA thioesters are ligands of hepatic nuclear factor-4alpha. Nature 1998;392:512-6

Kluck RM, Bossy-Wetzel E, Green DR, Newmeyer DD. The release of cytochrome $c$ from mitochondria: a primary site for $\mathrm{Bcl}-2$ regulation of apoptosis. Science 1997;275:1132-6

Liang YC, Wu CH, Chu JS, Wang CK, Hung LF, Wang YJ, Ho YS, Chang JG, Lin SY. Involvement of fatty acid-CoA ligase 4 in hepatocellular carcinoma growth: Roles of cyclic AMP and p38 mitogen-activated protein kinase. World J Gastroenterol 2005;11:2557-63

Monjazeb AM, High KP, Connoy A, Hart LS, Koumenis C, Chilton $\mathrm{FH}$. Arachidonic acid-induced gene expression in colon cancer cells. Carcinogenesis 2006;27:1950-60
Park JG, Lee JH, Kang MS, Park KJ, Jeon YM, Lee HJ, Kwon HS, Park HS, Yeo KS, Lee KU, Kim ST, Chung JK, Hwang YJ, Lee HS, Kim CY, Lee YI, Chen TR, Hay RJ, Song SY, Kim $\mathrm{WH}$, Kim CW, Kim YI. Characterization of cell lines established from human hepatocellular carcinoma. Int J Cancer 1995;62:276-82

Reid T, Ramesha CS, Ringold GM. Resistance to killing by tumor necrosis factor in an adipocyte cell line caused by a defect in arachidonic acid biosynthesis. J Biol Chem 1991;266:16580-6

Sapirstein A, Spech RA, Witzgall R, Bonventre JV. Cytosolic phospholipase A2 (PLA2), but not secretory PLA2, potentiates hydrogen peroxide cytotoxicity in kidney epithelial cells. J Biol Chem 1996;271:21505-13

Sung YK, Hwang SY, Farooq M, Kim JC, Kim MK. Growth promotion of HepG2 hepatoma cells by antisense-mediated knockdown of glypican-3 is independent of insulin-like growth factor 2 signaling. Exp Mol Med 2003a;35:257-62

Sung YK, Hwang SY, Park MK, Bae HI, Kim WH, Kim JC, Kim MK. Fatty acid-CoA ligase 4 is overexpressed in human hepatocellular carcinoma. Cancer Sci 2003b;94:421-4

Tang DG, Chen YQ, Honn KV. Arachidonate lipoxygenases as essential regulators of cell survival and apoptosis. Proc Natl Acad Sci USA 1996;93:5241-6

Wilson DB, Prescott SM, Majerus PW. Discovery of an arachidonoyl coenzyme A synthetase in human platelets. J Biol Chem 1982;257:3510-5

Yang J, Liu X, Bhalla K, Kim CN, Ibrado AM, Cai J, Peng TI, Jones DP, Wang X. Prevention of apoptosis by Bcl-2: release of cytochrome c from mitochondria blocked. Science 1997;275:1129-32 